\section{ノ- r}

[Nippon Nögeikagaku Kaishi

Vol.67, No. 2, pp. 145 147, 1993]

\section{ヒメハッカ (Mentha japonica \\ Makino）の自殖株の精油}

梅 本 和 泰

(名古屋学院大学化学教室)

平成 4 年 10 月 8 日受理

Essential Oil of Self-Pollinated Plants of

Mentha japonica Makino Containing

Menthone and Pulegone

(Chemical Constituents of Wild

Mints, part"X倓)

Kazuyasu UMEMOTO

Laboratory of Chemistry, Nagoya Gakuin

University, Kamishinano-cho, Seto, $480-12$

We studied the chemotypes of $S_{1}$ plants derived from the self-pollination of Mentha japonica Makino, which contains (menthone and pulegone as major components. Sixty-three plants were harvested when blooming and treated by steam distillation to yield essential oil. The components in the oil were detected by GC-MS and the amount of each component was expressed as a percentage of the total, in terms of the areas of the peak. Calculation was by a Chromatoprocessor combined with GC. These $S_{1}$ plants could be grouped into three chemotypes on the basis of the parent chemotype. Eighteen of the $S_{1}$ plants were similar to the parent ; 38. 2 61.1\% of the oil was menthone, and $20.3 \sim 40.7 \%$ was pulegone. Another chemotype was shown by 26 of the $S_{1}$ plants $; 60.1 \sim 68.4 \%$ of the oil was menthone, and $10.5 \sim 20.0 \%$ was pulegone. The third chemotype was that of the remaining $19 \mathrm{~S}_{1}$ plants, with $70.3 \sim 78.2 \%$ of the oil being menthone and $2.5 \sim 9.2 \%$ being pulegone. Oil of the parent and all $S_{1}$ plants contained 1.6 2.8\% borneol plus bornyl acetate. There were two kinds of plants, including the parent: those with $0.8 \sim$ $2.1 \%$ menthol pulus menthyl acetate, and those with $0.1 \%$ or less. (Received October 8, 1992)

本文を「野生ハッカの化学成分に関する研究」(第 18 報）上方る。前報は文献（1）。
ヒメハッカ (Mentha japonica Makino) は, わが国 固有の Mentha 属植物の1つである. かつては七メ六ッ カが各地任自生していた記録があるが，近年見出された といら報告はない。ヒメッッカの精油成分は, limonene の含量が $1 \%$ 以下であることを除けば，ニホンハッカ (Mentha arvensis L. var. piperascens Mal.) の変種, pulegone-menthone 系 ${ }^{(2)}$ 炕よく類似している。 メハッカの成分变種については, pulegone-menthone

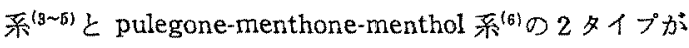
すでと報告されている.

今回, 育種している pulegone-menthone 系のヒメ八 ッカ種子から，自花受粉により発芽した自殖株 $S_{1} の 63$ 個体の精油成分を捈討した結果，若干の知見が得られた ので報告する.

ニホンハッカには，多くの成分变種があり，著者らも piperitenone oxide-piperitone oxide 系ニホンハッカの $\mathrm{S}_{1}$ 加, limonene-piperitenone oxide-piperitone oxide 系と， pulegone-menthol 系を分離した。このように，成 分変種が多い種は，その自殖株飞も成分変種の出現する 磪率が高いことが認められた(1,7)。一方，七メハッカは 成分変㣫が少ないので，その自殖株にも変種の出現する 確率が低いことが予想される。

1989 年 3 月, pulegone-menthone 系のヒメハッカの 種子から発芽した幼苗を, 直径 $25 \mathrm{~cm}$ 素焼き鉢人移植 し、育成したうらの63 個体が，翌年8～9月にかけて 開花した．各個体の植物形態は，親のそれと同一であっ た. 開花期に各個体の地上部 45 95 g を採取し，水蒸 気蒸留によって精油を $0.16 〜 0.22 \%$ 收率で得た. 親の 七メ八ッカ, 自殖試料の一部 $\mathrm{S}_{1}-5, \mathrm{~S}_{1}-16$ および $\mathrm{S}_{1}-30$ の精油の性状を Table I に示した。

次化, GC-MS 法 (Hitachi M-80 A, 20 eV) 加精油 中の成分を同定した．また，成分組成（\%) は，ガスク ロマトグラムのピーク面積比 (Chromatoprocessor 833 A, Hitachi $163 \mathrm{GC}$, Thermon $600 \mathrm{~T}, 0.3 \mathrm{~mm} \times 40 \mathrm{~m}$, $\left.70 \sim 210^{\circ} \mathrm{C}\left(2^{\circ} \mathrm{C} / \mathrm{min}\right)\right)$ から算出した，各精油の成分は, 親のそれと比烄検討した. Table II K親の七メハッカ, $\mathrm{S}_{1}-5, \mathrm{~S}_{1}-16$ および $\mathrm{S}_{1}-30$ の各精油成分と組成を示し た. Table III K自殖試料 $S_{1}-1 \sim 63$ について, 各精油 中の主要成分の割合から 3 系統に分けた。すなわら，親 之同じ pulegone-menthone 系 (Chemotype 1) が 18 個 体， menthone 主成分とし， pulegone 含量が 10.5 $20.0 \%$ のむの (Chemotype 2) が 26 個体, さらに, 
Table I. Properties of Essential Oil of $M$. japonica and Its $S_{1}$ Plants

\begin{tabular}{lccccc}
\hline & Fresh material & Yield of oil & $n_{\mathrm{D}}{ }^{20}$ & $d_{4^{20}}$ & {$[\alpha]_{\mathrm{D}}$} \\
\hline M. japonica & $1250(\mathrm{~g})$ & $2.31 \mathrm{~g}(0.18 \%)$ & 1.4602 & 0.8986 & $-5.4^{\circ}$ \\
$\mathrm{S}_{1}-5$ plant & $75(\mathrm{~g})$ & $145 \mathrm{mg}(0.19 \%)$ & 1.4558 & - & $-11.5^{\circ}$ \\
$\mathrm{S}_{1}-16$ plant & $85(\mathrm{~g})$ & $168 \mathrm{mg}(0.20 \%)$ & 1.4530 & - & $-18.4^{\circ}$ \\
$\mathrm{S}_{1}-30$ plant & $90(\mathrm{~g})$ & $185 \mathrm{mg}(0.21 \%)$ & 1.4620 & - & $-3.5^{\circ}$ \\
\hline
\end{tabular}

Table II. Composition of Oils of Mentha japonica and Its $\mathrm{S}_{1}$ Plants

\begin{tabular}{|c|c|c|c|c|c|}
\hline No. & Compounds & M. japonica & $S_{1}-5$ & $S_{1}-16$ & $S_{1}-30$ \\
\hline 2 & $\alpha$-Pinene & $1.6(\%)$ & $0.7(\%)$ & $1.3(\%)$ & $1.5(\%)$ \\
\hline 5 & Camphene & 0.3 & 0.2 & 0.3 & 0.3 \\
\hline 7 & $\beta$-Pinene & 1.5 & 0.6 & 1.0 & 1.5 \\
\hline 8 & Sabinene & 0.4 & 0.1 & 0.2 & 0.5 \\
\hline 9 & $\beta$-Myrcene & 0.2 & tr. & 0.1 & 0.1 \\
\hline 12 & Limonene & 0.5 & 0.4 & 0.5 & 0.4 \\
\hline 13 & 1,8-Cineole & 0.1 & $\operatorname{tr}$ & $\operatorname{tr}$ & 0.1 \\
\hline 16 & 3-Octanone & 0.2 & 0.2 & 0.2 & 0.3 \\
\hline 18 & p-Cymene & 0.2 & tr. & 0.1 & 0.2 \\
\hline 22 & $? m / z 43(100 \%), 101,143$ & 0.6 & 0.2 & 0.6 & 0.7 \\
\hline 24 & 1-Octen-3-yl-acetate & 0.1 & tr. & tr. & 0.1 \\
\hline 25 & 3-Octanol & 0.5 & 0.3 & 0.4 & 0.4 \\
\hline 28 & 1-Octen-3-ol & $\operatorname{tr}$ & tr. & tr. & $\operatorname{tr}$ \\
\hline 31 & Menthone & 44.0 & 57.3 & 72.6 & 39.9 \\
\hline 32 & Linalool & $\operatorname{tr}$ & tr. & tr. & tr. \\
\hline 34 & Isomenthone & 0.6 & 1.0 & 0.7 & 0.8 \\
\hline 43 & Menthyl acetate & 0.6 & $\operatorname{tr}$ & 0.7 & 0.7 \\
\hline 47 & Bornyl acetate & 1.7 & 1.8 & 1.7 & 1.6 \\
\hline 51 & $\beta$-Caryophyllene & 4.0 & 4.1 & 4.6 & 3.3 \\
\hline 55 & Menthol & 0.8 & $\operatorname{tr}$ & 0.5 & 0.7 \\
\hline 56 & Pulegone & 28.6 & 18. 1 & 2.5 & 32.6 \\
\hline 62 & $\alpha$-Humulene & 1.0 & 1.2 & 1.1 & 0.9 \\
\hline 64 & $\alpha$-Terpineol & $\operatorname{tr}$ & 0.2 & 0.1 & tr. \\
\hline 65 & Borneol & 0.4 & 0.8 & 0.6 & 0.3 \\
\hline 72 & Germacrene D & 0.4 & 0.1 & 0.2 & 0.3 \\
\hline 73 & Piperitone & 0.4 & 0.4 & 0.6 & 0.3 \\
\hline 75 & $\alpha$-Farnesene & 0.6 & 0.8 & 0.6 & 0.5 \\
\hline 89 & Geranyl acetone & 0.2 & 0.3 & 0.3 & 0.2 \\
\hline 93 & $? m / z 43,97,135,153(100 \%)$ & 0.5 & 0.6 & 0.7 & 0.6 \\
\hline 98 & Piperitenone & 0.1 & 0.1 & 0.1 & 0.1 \\
\hline 108 & Caryophyllene oxide & 1.7 & 1.9 & 2.0 & 2.5 \\
\hline 115 & $? m / z 43,82,109(100 \%), 138$ & 0.6 & 0.7 & 0.6 & 0.7 \\
\hline 124 & 2-Heptadecanone & 0.2 & 0.3 & 0.2 & 0.3 \\
\hline 128 & Thymol & 0.1 & $\operatorname{tr}$ & $\operatorname{tr}$ & 0.1 \\
\hline 141 & $? m / z 69(100 \%), 123,177,202$ & 0.3 & 0.3 & 0.4 & 0.3 \\
\hline 148 & $? m / z 43,69(100 \%), 135,204$ & 0.3 & 0.5 & 0.6 & 0.4 \\
\hline 164 & $? m / z 57(100 \%), 95$ & 0.4 & 0.4 & 0.5 & 0.5 \\
\hline \multirow[t]{2}{*}{168} & Phy tol & 1.8 & 0.8 & 1.0 & 1.9 \\
\hline & Others & 4.5 & 5.6 & 4.0 & 4.4 \\
\hline
\end{tabular}

Mentha japonica and its $S_{1}$ plants were harvested at blooming time (September 3,1990) and were distilled with steam to yield each oil. Compounds in the oil were detected by means of GC-MS method, which was measured at $20 \mathrm{eV}$ using Hitachi M-80 A. Peak area percentage of compounds was calculated by Chromatoprocessor 833-A combined with Hitachi 163-GC using Thermon 600 T (SCOT), $0.3 \mathrm{~mm} \times$ $40 \mathrm{~m}$ glass capillary column at $70 \sim 210^{\circ} \mathrm{C}\left(2^{\circ} \mathrm{C} / \mathrm{min}\right)$. tr.: less than $0.1 \%$. 
Table III. Three Chemotypes Grouped from Contents of $63 \mathrm{~S}_{1}$

\begin{tabular}{lccr}
\hline & $\mathrm{S}_{1 \mathrm{~s}}$ & $\begin{array}{c}\text { Menthone } \\
(\%)\end{array}$ & $\begin{array}{c}\text { Pulegone } \\
(\%)\end{array}$ \\
\hline Chemotype 1 & 18 & $38.2 \sim 61.1$ & $20.3 \sim 40.7$ \\
Chemotype 2 & 26 & $60.1 \sim 68.4$ & $10.5 \sim 20.0$ \\
Chemotype 3 & 19 & $70.3 \sim 78.2$ & $2.5 \sim 9.2$ \\
\hline
\end{tabular}

menthone 含量の高い系統 (pulegone 含量が $9.2 \%$ 以 下, Chemotype 3) が 19 個体それぞれあった。

1991 年, menthone 主成分 (Chemotype 3) の各 $\mathrm{S}_{1}$ 《ついて, 開花前から開花初期に採取した油分は，pule gone の含量が 18〜30\%であった。また, Chemotype 1 の各 $S_{1}$ にいて，開花衰退期の採油分は，いず れ pulegone 含量が数\%に滅少し, menthone 含量が $70 \%$ 以上になった。このよらに，時期的に pulegone か 5 menthone 入比較的容易に推移することがわかった。 したがって，ヒメハッカの親および各 $\mathrm{S}_{1}$ は，開花前て は pulegone と menthoneを主成分とし，開花期には，

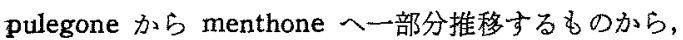
大部分推移するものとの個体差であると考えられる。し かし最終的には，pulegone-menthone 系ニホンハッカ (北海道クサハッ力) 主成分になるか， menthol までは推移しなかった。

精油中の少量成分として, borneol と bornyl acetate がヒハハッカ特よびその $\mathrm{S}_{1}$ K共通して数\%含有するこ とがかかった。 しかし，既報(3 6)のとメハッ力の精油に 性, borneol 関連化合物が検出されていないのでこれ らの化合物を含む系統と，含まない系統があることも考 えられる. 一方, menthol と menthyl acetate は数\%含 をものと，仼とんど含むないものとがあり、Chemotype
1，2，3 のいずれにも，このような傾向が認められた. 藤田らが報告した， menthone から menthol まで推移す る, pulegone-menthone-menthol 系 ${ }^{(5)} の$ 出現を期待した が得られなかった，今回の自殖株の試験から、ヒメハッ カは，主要成分を基準にして成分系考考察した場合，成 分変種の形成しがたい種であるといるる。これはとメハ ッ力の安定な遗伝子によるものであるら。なお，少聂成 分の menthol および borneol 両関連化合物の含量の比 較から，成分系を考察する余地があるよらに考古られ る.

最後に本文をましめるにあたり，上メハッカの分布出 よび分類について飯田女子短期大学清水純夫博士にご教 示いただいた。また，ヒメハッカの各 $\mathrm{S}_{1}$ の精油成分の GC 乩よび GC-MS 分析は, 長岡香料(株)大阪研究所古 III 靖博士ならびに仁井愺迪博士にご協力いただいた。

これらの方ネ煌く和礼申し上げ事す。

（1）梅本和泰，恒屋知之：農化，65，1647-1650 (1991).

（2）梅本和泰：名古屋学院大学論集 (人文・自然), 23, 7-36 (1987)

(3) S. Shimizu, N. Ikeda, and H. Ueda : Perfum. Essent. Oil Rec., 51, 657-660 (1960)；清水純 夫, 池田長守, 上田博夫，星野和美：香料，67， 17-22 (1962).

(4) 中山孟郎, 松山正行 : 香料, 72, 25-28 (1963).

(5) S. Fujita and Y.Fujita : Agric. Biol. Chem., 34, 1511-1515 (1970).

（6）藤田真一，中野敏子，藤田安二：農化， 51, 405-408 (1977).

（7）海本和泰, 恒屋知之: TEAC 講演要旨, 34 , 166-167 (1990) ; 梅本和泰, 恒厔知之 : 農化, 64, $1467-1469$ (1990). 